\title{
CONSIDERATIONS FOR BRITTLENESS IN TAILINGS
}

\author{
JiŘí HERZA ${ }^{a, *}$, RYAN SINGH ${ }^{b}$ \\ ${ }^{a}$ Czech Technical University in Prague, Faculty of Civil Engineering, Depatment of Geotechnics, Thákurova 7, \\ 16629 Prague, Czech Republic \\ ${ }^{b}$ HATS Consulting, 118 St Georges Terrace, Pert, WA 6000, Australia \\ * corresponding author: jiri.herza@fsv.cvut.cz
}

Abstract. Brittleness is an important geotechnical parameter of soils as it describes the degree of reduction of the soil shear resistance after reaching the peak strength. [1] described soil brittleness by means of a brittleness index $\left(I_{B}\right)$, which is the ratio of the shear resistance loss to the peak shear strength. The $I_{B}$ has become a common soil parameter that is used as an indicator for the soil susceptibility to liquefaction.

However, $I_{B}$ does not consider the rate at which the soil resistance reduces, the development of excess pore water pressure and it ignores the stress strain relationship. As a result the same $I_{B}$ can be calculated for a soil that collapses over a very small strain range and a soil that gradually reduces its shear resistance over extensive strain levels as long as both soils have similar peak and residual shear strengths.

This paper discusses the root causes of the shear resistance loss and proposes a modification of the $I_{B}$ parameter to take account of the rate of the shear resistance loss, which will help to better depict the stress-strain behaviour of strain softening soils. This paper also distinguishes between structural brittleness and undrained brittleness and provides a clear definition of each to improve the understanding of tailings among practitioners.

Keywords: Brittleness, critical state, shear resistance, tailings.

\section{INTRODUCTION}

Following the failures of the tailings dams at Samarco (Fundão) and Brumadinho (Feijão) in Brazil, brittle failure has become a topic of great interest within the geotechnical engineering community. Brittle failure has been identified to be a contributing factor in the failures of many tailings storage facilities, as described by [2 4] and others. The post-failure review of the Feijão Dam [4] identified that the sudden failure of the dam was caused in part by tailings exhibiting brittle behaviour. Of concern to the mining industry was the finding that there were no apparent signs of distress prior to failure, which is in fact a fundamental characteristic of brittle failure. It should be noted that the lack of indication of distress was not due to a lack of monitoring instrumentation for the dam which featured 113 piezometers, 14 surface survey markers, six inclinometers and 50 monitored seepage points.

The industry's concern regarding the presence of brittle materials within and supporting tailings dams, particularly in those featuring upstream raises is evident in the requirements of the newly published Global Industry Standard on Tailings Management ("the Global Standard"), which includes Requirement 4.6 that reads "Identify and address brittle failure modes with conservative design criteria." (Global Tailings Review, 2020). This requirement is also reflected in several other design guidelines, such as Australian National Committee on Large Dams [5] Guideline on Tailings Dams [6], which provides recommendations for conservative design assumptions if materials are found to be susceptible to static liquefaction, which is noted to be a brittle subset of contractive materials. Other forthcoming publications, guidelines and papers - including the forthcoming International Commission on Large Dams (ICOLD) Bulletin on tailings dam safety (ICOLD, in progress) and the International Council on Mining and Metals (ICMM) Tailings Management Good Practice Guide (ICMM, 2021) identify the identification of brittle failure modes as a critical evaluation factor for dam safety that should be a primary consideration in the design and review of tailings storage dams.

Despite the recent - and perhaps overdue - emphasis on brittleness and its importance to tailings dams, the meaning of brittleness and methods to characterize it currently lacks certain aspects of clarity and alignment with how it is not being used. Further, the concept may not be fully understood by some professionals involved in evaluating and designing these facilities.

Generally, the use of the term "brittle" in the context of recent tailings dam failures and in the various standards and guidelines that refer to brittle behaviour alludes to a sudden loss of shear strength without signs of prior deformation.

However, the currently available definition for soils as proposed by Bishop (1967) does not fully align with this interpretation, namely the aspect of suddenness. Without a formal definition of brittleness that reflects 
the intended use, the meaning or measure of terms like "brittle material or brittle failure mode" is left to the individual interpretation of the reader.

\section{BRitTleness InDEX}

Bishop's index (Bishop, 1967) relates the peak shear strength $\left(\tau_{p}\right)$ to the residual shear strength $\left(\tau_{r}\right)$ as follows:

$$
I_{B}=\frac{\tau_{p}-\tau_{r}}{\tau_{p}}
$$

The index provides a sense of the magnitude between the peak and residual shear stresses, with a higher index indicating a greater difference between the peak and residual resistance of a material.

The $I_{B}$ proposed by Bishop does not consider the strain (deformation) levels at which a brittle failure is initiated or the strain at which the residual strength is achieved. The importance of strain has been well recognised in the field of rock mechanics, where it has been identified that the brittleness of a rock mass provides insight into how the rock mass will behave for various applications, e.g. hydraulic fracturing, drilling rate, dust generation, etc. [7]. Over a dozen brittleness indices have been developed for use in rock mechanics to capture the various aspects of material strength loss, including consideration of the strain range within which the loss occurs [8].

[1] recognised that $I_{b}$ did not consider the suddenness of the shear strength loss and thus he also introduced the concept of brittleness in terms of the additional energy required to progress the shear failure from the peak $\left(\mathrm{E}_{p}\right)$ to the residual state $\left(\mathrm{E}_{f}\right)$ as shown in Figure 1 .

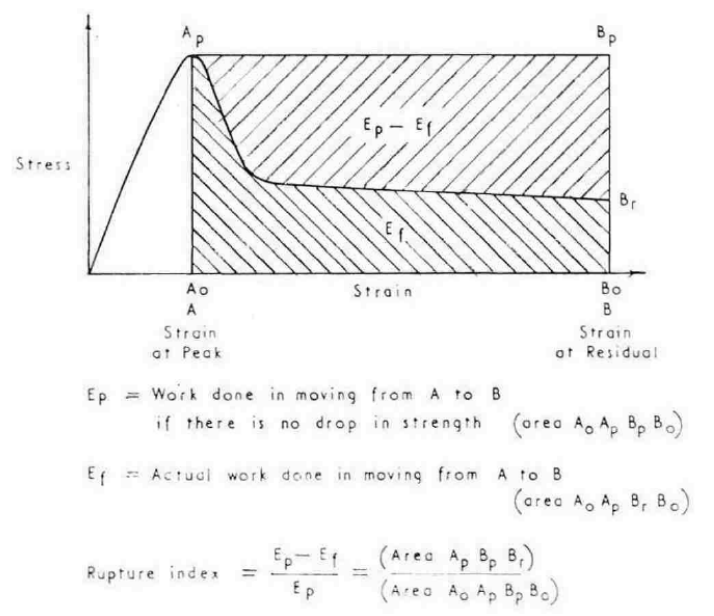

FiguRE 1. An energy parameters for brittle soils (Bishop, 1967).

While the rupture index (introduced in Figure 1) considered the suddenness of the shear strength loss, 11 recognised that the shape of the stains-stress line past the failure is strongly dependant on numerous parameters including test type, test procedure, sample preparation, geometry etc. As a result the rupture index has not been adopted by the geotechnical community and the strain considerations in the brittleness assessment for soil have not been addressed in the literature.

In addition, Bishop's work was focused on clays, whereas tailings frequently (but not exclusively) occur as cohesionless silts and sands. While the magnitudebased Brittleness Index may be useful in both cohesive and cohesionless materials, the mechanism of strength loss is typically different between the two classes of materials, as discussed further below, and the strain levels at a which brittle failure occurs may vary significantly. 4 thus proposed renaming Bishop's Brittleness Index as the "Strength Loss Index" because it considers solely the strength and not the strain aspects of brittleness.

\section{Different Types of Brittleness}

The research leading to the definition of Bishop's $I_{B}$ was primarily focused on the behaviour of plastic clays. The shear strength reduction depicted in Bishop's work was the result of the clay particles reorientating along the developing shear plane. [1, 2] drew attention to the decreasing shear resistance of plastic clays caused by the development of continuous bands of strongly orientated particles, which resulted in the strength of the clays lowering to a residual value.

[2] observed the development of strains and displacement during simple shearing of the kaolin clay fabric. Figure 2 (left) shows successive sections of kaolin clay, which were interrupted at various stages of shearing. Each section has been labelled (e.g. V.2, V.3, etc.), to show the position of the section on the adjacent stress-strain curve. As can be seen, the development of structural strains and displacements of the clay structure coincides primarily with an increase in the peak strength as the original clay structure rotates (V.3). In the post-peak phase of shearing, discontinuities of the structure occur with progressive reorientation of the clay particles occurring at discontinuities (Figure 2, right). Once the clay minerals had reorientated along the direction of strain, the residual shear strength of the clay was reached. The originally proposed Brittleness Index therefore relates the loss of shear strength of the material to the structural change of the material caused by straining, which is an irreversible phenomenon.

Strain-induced shear strength loss also occurs in granular materials where the soil particle and intraparticle bonding can be compromised by shearing. In sandy soils, the structure of the sand and sand-like particles can be crushed and grinded as the particles move over and around each other during shearing. This change to the particles and intra-particle contacts can result in a reduction of the frictional resistance of the soil during shearing. This loss in shear strength is intensified for cemented granular materials in which straining can break the cementitious bonds resulting 
in a sudden (and potentially large) drop in the shear strength of the material. Figure 3 shows an example of cemented aggregates of bauxite residue in which sandsite particles are composed of much smaller particles interconnected by iron oxide and aluminium hydroxide minerals.

Although it is acknowledged that the properties of soils change in time, the structural changes and the peak and the residual strength can be considered, for the purpose of this paper, as lasting properties of the soil induced by straining. In line with the original Bishop's brittleness concept, the shear strength in the context of this paper is considered to be a soil property that depends primarily on the soil composition and structure. In comparison, shear resistance is hereby defined as the ability of a soil to withstand shear stress under a given set of conditions.

It must be emphasised that a generic function of the shear resistance has numerous parameters, some of which may still be unknown. The influencing parameters include the void ratio, soil composition, stress history, level of structuration, temperature, strain, strain rate and structure. The limitations of our testing and computing methods do not allow us to fully quantify the influence of these parameters; thus, the shearing relationships are simplified, such as in the Mohr-Coulomb equation which is the most common expression of the shear resistance of soils. The shear strength of a soil in the Mohr-Coulomb equation is expressed by the indices of an effective friction angle $\left(\phi^{\prime}\right)$ and an effective cohesion $\left(c^{\prime}\right)$ and the shear resistance of the soil at failure $\left(\tau_{f}\right)$ is expressed as:

$$
\tau_{f}=c^{\prime}+\sigma_{n}^{\prime} \tan \phi^{\prime}
$$

where $\sigma_{n}^{\prime}$ represents the normal effective stress acting on the shear surface, the sole variable in the relationship.

To illustrate the concept of shear strength as a soil property and shear resistance as a function of stress conditions, the $\phi^{\prime}$ value has a definite minimum value that is greater than zero. However, the normal effective stress could reduce to zero due to significant increase in pore water pressures.

Using the example of the Feijao tailings dam, the cause for the loss of shearing resistance was the rapid and significant increase of pore water pressures, which reduced the effective normal stress variable $\sigma_{n}^{\prime}$ to zero or near zero and resulted in a liquefaction of the tailings. The generation of excess pore water pressure was caused by the contractive nature of the tailings in which the collapse of the loose aggregate assembly transferred the stress from the interparticle interfaces to the water. It is noted that the breakdown of the iron oxide bonds (similar to those shown in Figure 3 reduced the effective cohesion value of the Feijao tailings. However, it is unlikely that the frictional resistance between particles, represented by $c^{\prime}$ and $\phi^{\prime}$, changed in any substantial way and was the root cause of the failure.
Because of the major differences between the described processes leading to the reduction of the soil's ability to resist shear stress, it is proposed that shear resistance loss caused the irreversible change of the soil's structure as described by [1] and others be referred to as structural brittleness. The sudden loss in a soil's shear resistance caused by excess pore water pressure should then be referred to as undrained brittleness.

It is recognised that both types of brittleness can occur simultaneously, as structural brittleness can also lead to undrained brittleness and many soils can lose shear resistance due to a combination of shear strength reduction and excess pore water pressure generation. However, an understanding of the different underlying phenomena leading to a shear resistance loss is crucial because the minimum recommended Factors of Safety that are currently used to prevent embankment failures do not account for misconceptions of the underlying geotechnical processes [5].

\section{Structural Brittleness And The RATE of Strength Loss}

As discussed earlier, the current brittleness index alone lacks a measure of the suddenness of a material's resistance or strength loss, with Bishop's rupture index indirectly providing a method to assess the strain over which shear resistance is lost.

A more direct consideration of the strain range over which the loss of shear strength occurs was assessed by estimating the rate of the greatest reduction in shear strength after the peak shear strength is reached normalised by the peak shear strength, as shown in Figure 4 with the stress stain data adopted from [2] (V7 plot in Figure 2, with the data translated to SI units). This calculated value, called the brittleness slope (BS), provides for the aspect of "suddenness" of strength loss and expresses the percentage of the peak shear strength loss per $1 \mathrm{~mm}$ of shear strain.

To illustrate the application of the BS, the index was calculated for sands and clays with available direct shear test data. Of particular interest was the application of the index for sands of varying cementation, density in the form of relative density/void ratio and normal effective stress.

Direct shear test data for sands was obtained from [10, 11]. The tests were completed on uncemented samples and with an addition of $1 \%$ and $2 \%$ of cement and at different normal effective stresses. Additional ring shear tests on interparticle bonded bauxite residue (Figure 3) were also completed for the purpose of this study.

For a comparison to the above non-plastic soils direct shear test data for clays was also included, based on direct shear tests for a clay material presented by [12] and the shear box test results from 2. Bishop's brittleness index and the brittleness slope for the referenced tests are shown in Figure 5. 

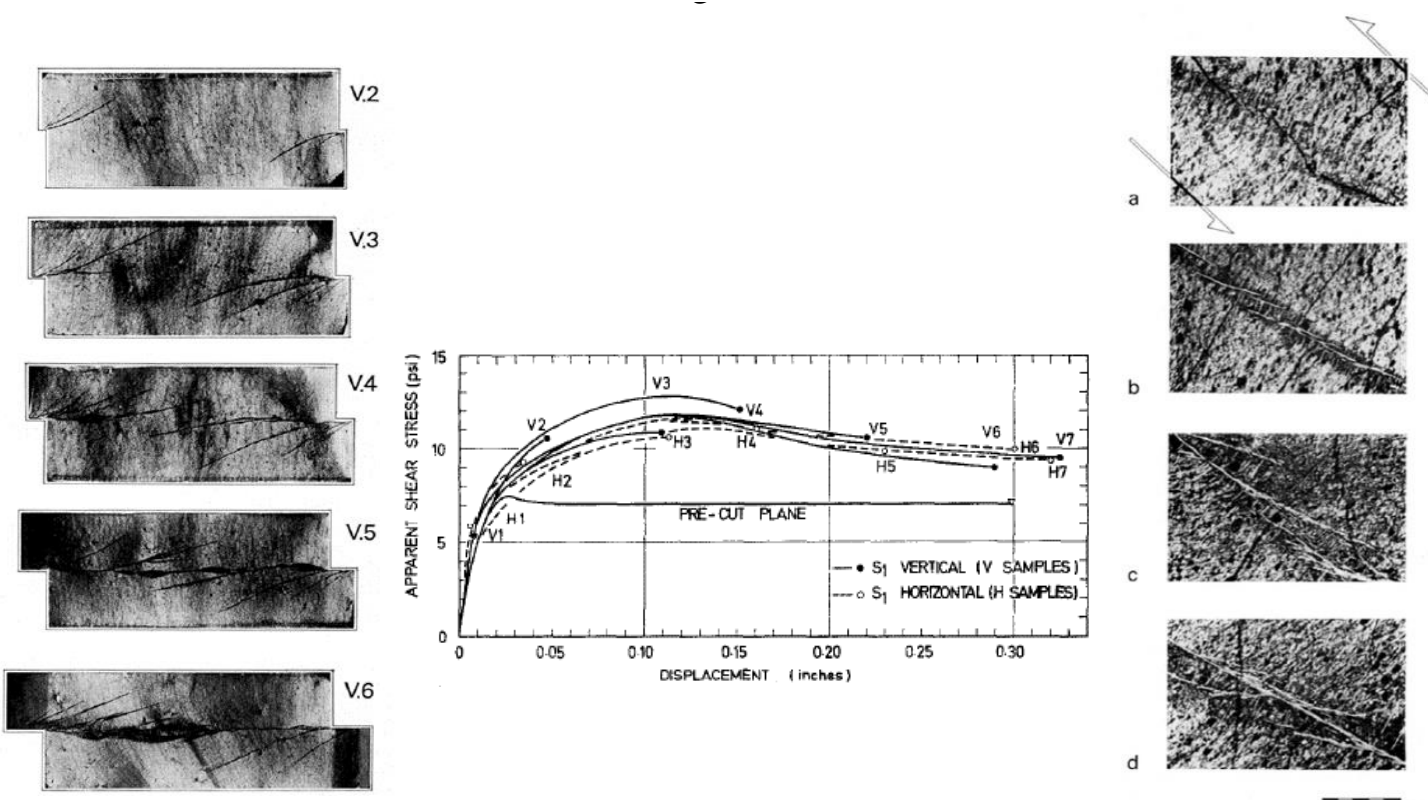

FIGURE 2. Sequence of kaolin clay structures sheared normal to original clay fabric (left) and sequential development of discontinuity with arrow indicates direction of shearing (right) 2 .
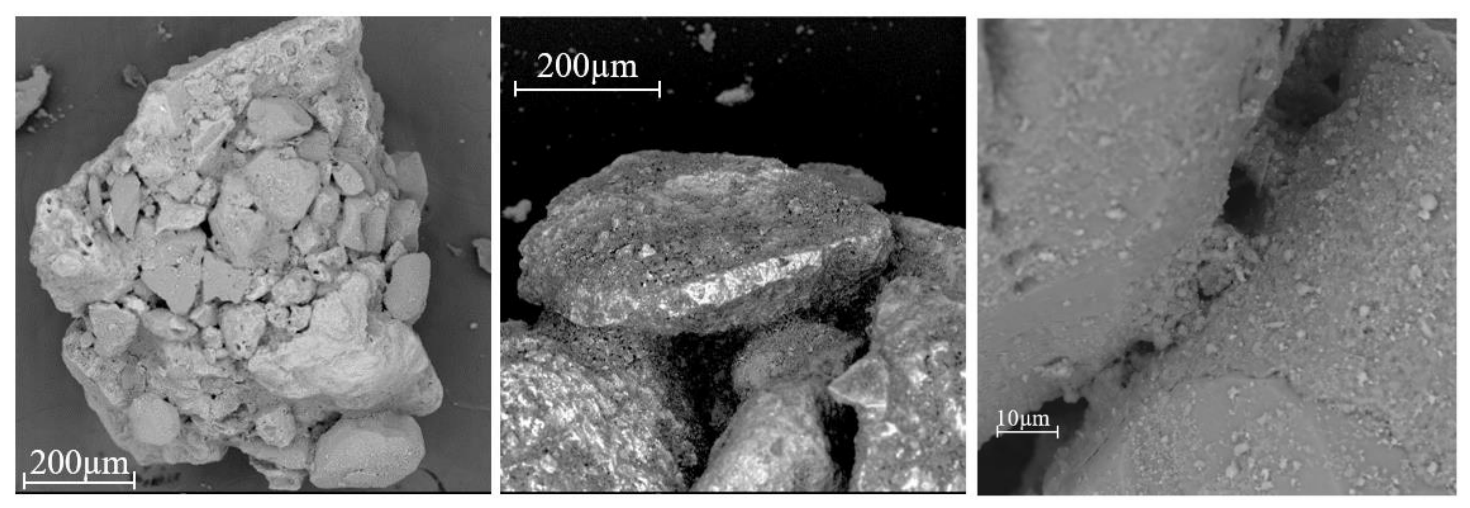

Figure 3. Cemented aggregates of bauxite residue [9].

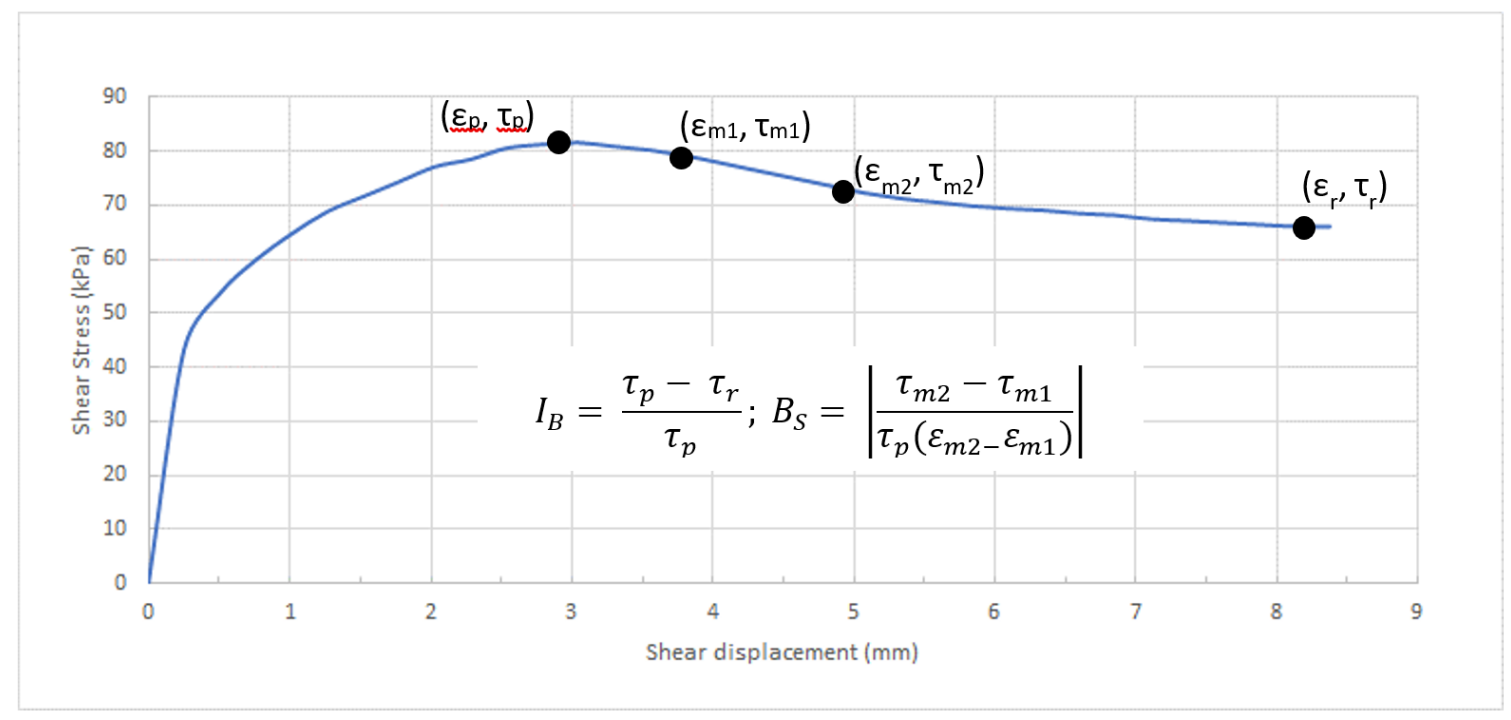

Figure 4. Brittleness Index for Strength Loss. 
A "Zone of High Brittleness" has been overlaid on the Structural Brittleness Plane to identify areas where $I_{B}$ is greater than 0.4 . This $I_{B}$ threshold has been adopted from [4. It should be noted that this value of 0.4 was selected as a threshold by Robertson as available data for flow liquefaction failures indicated a correlation of brittleness and liquefied undrained shear strength ratios. In reviewing the conclusions in [4, it is likely that structural brittleness and undrained brittleness has been combined for several reasons, including the testing being carried out in undrained conditions leading to the generation of excess pore water pressures. Nonetheless, where $I_{B}$ values greater than 0.4 are observed it indicates that particular attention should be given to the potential for some form of brittle behaviour.

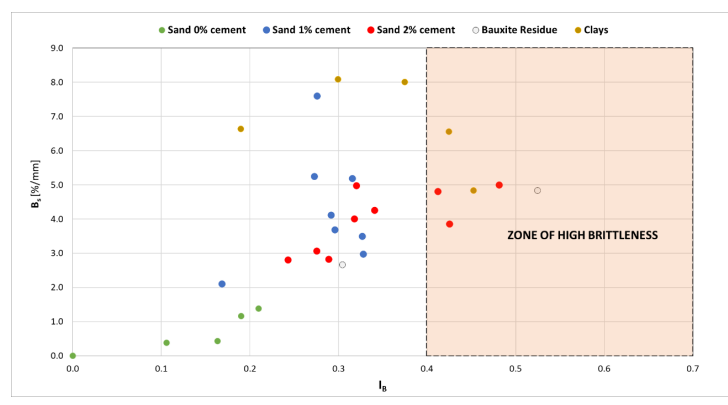

Figure 5. Structural Brittleness Plane.

The analysed test results indicated that:

- Brittleness of clean uncemented sand is smaller compared with the brittleness of the cemented materials and it increases with the increasing sand density as expected.

- Increasing cement content increases the peak shear strength, the dilatancy and the $I_{B}$ and $B_{s}$ values. It also results in the peak shear strength being achieved at lower shear displacements.

- Increasing normal stresses by $100 \%$ supresses the dilatancy and the $I_{B}$ and $B_{s}$ values of the samples with $2 \%$ cement content. However, the increase of normal stress had only a very little impact on the samples with $1 \%$ of cement added.

- The spread of the points in Figure 5 is most likely a result of the non-linear relationships between the sand density, cement content and the applied effective stress. In addition, several of the presented stress paths did not converge to the same residual shear strength at the same normal stress, indicating that the shearing may not have destroyed all cemented bonds within the sand samples.

- The test results of the bauxite residue were showing brittleness caused by gradual destruction of the intra-particle bonds only on comparatively denser samples where the loss of shear strength was accompanied by the sample contraction. This behaviour contrasted with the behaviour of the cemented and uncemented compacted sands that exhibited dilation after reaching the peak shear strength.

- The bauxite residue samples reached the peak shear strength values at higher displacement compared to the artificially cemented sands.

For clays, it was noted that the range of brittleness varied significantly and the Brittleness Slope reduces with an increasing brittleness index. However, it is likely that due to the low permeability of the tested clays some of the measured loss of shear resistance was due to the development of shear-induced porewater pressures.

In relation to the brittle behaviour identified in recent tailings dam failures, structural brittleness of the tailings was not the primary trigger mechanism, nor can it necessarily indicate that undrained brittleness is likely.

As expected, the test results of loose uncemented clean sands did not show structural brittleness as the samples contract during drained shearing and the tighter packing of sand particles made shearing harder. Conversely the same sands, but in a denser state, indicated moderate structural brittleness as they dilated under shearing.

If saturated and tested in undrained (constant volume) conditions, the dilative sands would gain shear resistance due to reduced pore pressures generated during shearing. In contrast the loose sands tested in undrained conditions would show a loss of shear resistance during shearing due to shear induced excess pore water pressures. It can therefore be seen that for uncemented clean sands, the tendency or likelihood for structural and undrained brittleness are opposed.

In cemented sands however, the structural brittleness may indicate the potential for undrained brittleness and liquefaction. In the case of drained conditions, structural brittleness can be observed for loose and cemented sand, as the cementitious bonds break, resulting in a collapse of the soil, or particle structure followed by further contraction. This behaviour was observed in the test results of the bauxite residue sample. Under undrained conditions, this tendency for contractive behaviour would not be able to develop and would instead translate into generation of excess pore water pressures, a reduction in normal effective stress and loss of shear resistance potentially to the point of liquefaction.

As such, structural brittleness can be used as a screening assessment for the potential of Undrained Brittleness and even liquefaction for loose and cemented sands. This relationship could be made even clearer, with a three-dimensional path of shear stress, shear strain and volumetric change (reduction). The volumetric change is perhaps a better indication of structural change than a void ratio for cemented materials as the change of the structure (breakage of particles) may not necessarily be reflected by the change of the void ratio. 


\section{UNDRAINED BRITTLENESS}

As discussed earlier, the undrained brittleness refers to the loss of shear resistance of a soil due to the straininduced pore water pressures. This type of brittleness is caused by a rapid increase of pore water pressures when the soil structure decays in so-called undrained conditions. Such conditions occur in contractive, fully or partially saturated soils when the strain-induced porewater pressures do not concurrently dissipate. Under such conditions, the loss of shear resistance is proportional to the reduction in effective confining stress in the soil.

With the available testing apparatus, given excess porewater pressure generated in the shear zone cannot be directly measured using the current laboratory equipment, it is being inferred from observations made at the boundaries of the sample. Together with the other influencing factors discussed earlier, this makes the conventional strain-stress diagrams unsuitable for description of the undrained brittleness. Instead, the concept of Critical State Soil Mechanics (CSSM) provides an indication of the likelihood of a brittle failure, and this indeed has become common practice in the tailings industry.

The use of the state parameter to assess a soil's likelihood of brittle failure is based on the distance between the current state of the soil from its critical state, as expressed by a Critical State Line (CSL). The CSL is a locus of critical states, at which continuous shearing occurs without a change of mean effective stress $\left(p^{\prime}\right)$, deviatoric stress $(q)$ and void ratio $(e)[3]$. Due to its dependency on the void ratio as a measure of the soil structure, the CSSM concept is not directly applicable to all materials, in which the orientation of aggregates and/or cementation plays an important role such is the case of the kaolinite clays and cemented sands discussed earlier in this paper.

The CSL of a soil is commonly depicted as a relationship between mean effective stress and void ratio, with any point on the plane representing a soil's state prior to shearing. An example of a CSL is shown in Figure 6 3]. Per CSSM, any soil being sheared will tend towards the CSL as the soil structure decays from the initial state to the critical state.

During undrained shearing of a soil, volumetric changes are prohibited and the shear stress path towards the CSL is horizontal with respect to the CSL plot as shown in Figure6.

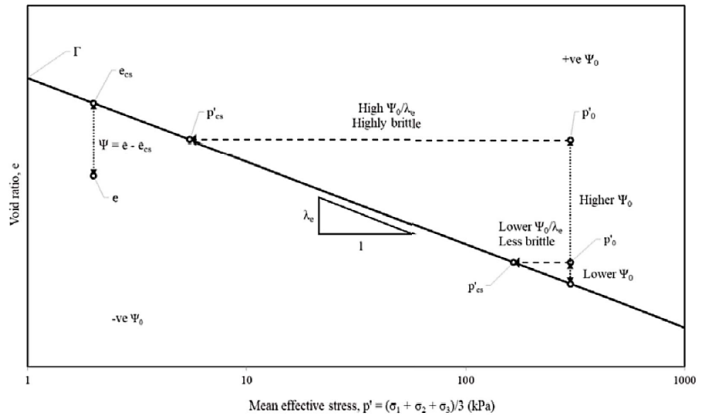

Figure 6. CSL 13 .

The pre-sheared state of the soil is often described using a state parameter, $\psi_{o}$, which is the difference in the pre-sheared state and the critical state void ratios at the same mean effective stress (Figure 6). A stress path following the vertical direction of the state parameter $\psi_{o}$ can be obtained from a direct shear tests at a constant normal stress undertaken in perfectly drained conditions. However, as the undrained brittleness is caused by reduction of the mean effective stress in undrained shearing, the state parameter $\psi_{o}$ alone is not sufficient to capture the potential for brittle failure. The susceptibility to brittle failure, rather, is proportional to the horizontal distance between the pre-sheared mean effective stress $\left(p_{o}^{\prime}\right)$ and the effective stress at the CSL at constant $\left.p_{c s}^{\prime}\right)$ which is equivalent to the ratio of the state parameter $\psi_{o}$ and the CSL slope $\left(\psi_{o} / \lambda_{e}\right)$ as shown in Figure6. A greater $\psi_{o} / \lambda_{e}$ indicates a greater potential for generation of excess pore water pressures during undrained shearing and thus a greater likelihood of brittle failure.

[13. presented results of critical state lines for various tailings, which demonstrated that the CSL cannot be reliably constructed from basic soil characterisation tests and CSL specific testing is crucial to understand the potential for undrained brittleness.

\section{Discussion And Conclusions}

This paper proposes to clarify terms for brittleness to align them with the use of the term brittle as it pertains to a soil exhibiting a sudden loss of shear strength without signs of prior deformation, particularly in the context of recent tailings dam failures. In this context the two following forms of brittle behaviour are identified:

- Structural brittleness - a loss of a soil's shear strength caused by irreversible change to a soil's structure during shearing, that can occur in clays and cemented soils

- Undrained brittleness - a loss in a soil's shear resistance due to a change in the stress field applied to a material, often due to generation of excess pore water pressures

The structural brittleness can be captured by Bishop's $I_{B}$ using conventional strain-stress plots although the rate of the shear strength loss can be 
treated with caution due to its dependence on the testing procedure. Modern investigation techniques such as SEM can be successfully applied to reveal the nature of the soil structure at the microscopic level and thus its susceptibility to structural brittleness.

The undrained brittleness is the result of excess pore water pressure generated during undrained shearing and the use of $I_{B}$ estimated from stress-strain plots is considered insufficient. Although the IB can used as a screening tool, the undrained brittleness should be considered using the CSSM concept.

A state parameter $\psi_{o}$ greater than -0.05 (a dashed parallel line to the CS, in Figure 7 is commonly taken as an indication of contractive soils that may be susceptible to brittle failure. Rather than using $\psi_{o}$ alone, the likelihood of brittle failure should be expressed by the $\psi_{o} / \lambda_{e}$ ratio with increasing values indicating a higher likelihood of undrained brittleness.

The potential susceptibility to undrained brittleness is indicated by shading of zones in Figure 7 Because not all contractive soils are susceptible to brittle failure, further delineation of the zones may be appropriate using the $\psi_{o} / \lambda_{e}$ value. As Figure 7 shows a log-linear relationship between the mean effective stress and the void ratio, the potential boundary of undrained brittleness may by a curved line as indicated in Figure 7. The authors emphasise that the potential boundary of undrained brittleness is indicative only and it is not based on any testing.

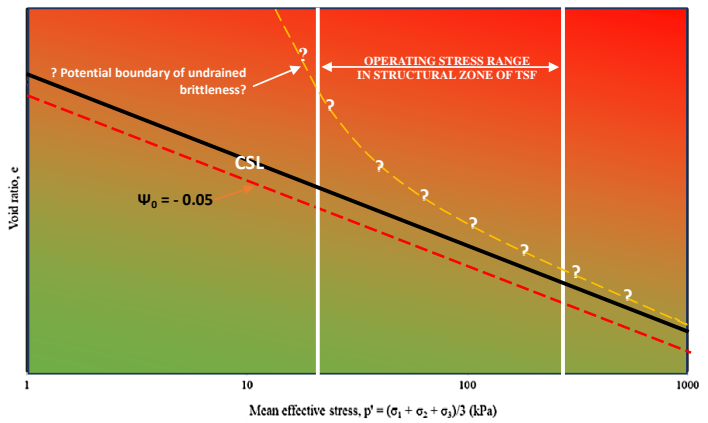

Figure 7. CSL and critical zones.

Beyond considering this state parameter delineation, further definition can be added to a CSL plot in order to better define the area of concern. The authors propose that the assessment should focus on the range of mean effective stresses that the soil can be exposed to under the current and future loading conditions. This range includes the current conditions at relevant depths and the pressures imposed by potential development and closure of the TSF. This is important because:

- Soils that would only exhibit undrained brittleness under mean effective stresses well outside the operation stress range can be defensibly deemed not to pose a concern for the structure.

- Soils that are dilative in the current state can become contractive and potentially susceptible to undrained brittleness if the mean effective stress increases due to the future TSF development or closure.

The authors propose that consideration of appropriate mean effective stresses be included in the assessment of materials susceptible to undrained brittleness in the design and assessment of all civil structures, including TSFs. To support this, the derivation and application of tailings-specific CSLs are critical, as recommended by [13].

It should also be noted that the use of the state parameter to identify a material's susceptibility to brittle failure is dependent on a material's void ratio, and any materials that do not exhibit a meaningful change in void ratio during brittle failure, such as cemented sands or structured clays, cannot be appropriately assessed within this framework. Thus, further research into other appropriate measures of a material's structure may allow a wider assessment of brittle behaviour in soils and tailings, in particular.

Future work extending from this paper include further definition and characterisation of the causes and mechanisms of undrained brittleness, as well as some proposed index to measure the susceptibility of a material to feature undrained brittleness and thus a formal potential boundary of undrained brittleness. This will allow a characterisation of materials that may be susceptible to undrained brittleness, which aligns with the principles of the Performance Based, Risk Informed approach to storage facility safety.

\section{ACKNOWLEDGEMENTS}

This work was supported by the Grant Agency of the Czech Technical University in Prague, grant No. SGS21/045/OHK1/1T/11.

\section{REFERENCES}

[1] A. Bishop. Progressive failure with special reference to the mechanism causing it. 1967. Proceeding of the geotechnical conference, Oslo, Sweden. Vol 2., page 142, 150.

[2] N. Morgenster, J. Tchalenko. Microscopic Structures in Kaolin Subjected to Direct Shear. 1967. J.S. Geotechnique 17: 309-328.

[3] M. Jefferies, K. Been. Soil Liquefaction - A critical state approach. 2016. Taylor \& Francis, London.

[4] P. Robertson. Evaluation of Flow Liquefaction: influence of high stresses. 2017. Proceedings from 3rd International Conference on Performance Based Design in Earthquake Geotechnical Engineering.

[5] J. Herza, M. Ashley, J. Thorp. "Factor of Safety? - Do we use it correctly?". 2017. ANCOLD 2017 Conference, October 26-27, 2017. Hobart, TAS, Australia.

[6] Guidelines on Tailings Dams - Planning, design, construction, operation and closure - Revision 1. 2019. ANCOLD. July 2019.

[7] H. Zhou, J. Lu, Y. Jiang, F. Meng. A New Rock Brittleness Evaluation Index Based on the Internal Friction Angle and Class I Stress-Strain Curve. 2018. Rock Mechanics and Rock Engineering Vol. 51. 
[8] J. Jiang, W. Dong, H. Xinping, D. Shuai. Relationship between a Brittleness Index and Crack Initiation Stress Ratio for Different Rock Types. 2020. Advances in Civil Engineering, vol. 2020, Article ID 8091895, 12 pages.

[9] J. Herza, D. Jirasko, I. Vanicek. The influence of aggregates on tailings behaviour. 2020. Proceedings of the WMESS Conference, Prague, September 2020.

[10] Y. Amini, A. Hamidi, E. Asghari. Shear Strength Characteristics of an Artificially Cemented Sand-Gravel Mixture. 2013. Challenges and Recent Advances in Geotechnical and Seismic Research and Practices, Chengdu, China. October 25-27, 2013.
[11] A. Simoni, G. Houlsby. The Direct Shear Strength and Dilatancy of Sand-gravel Mixtures. 2006.

Geotechnical and Geological Engineering. 24. 523-549., https://doi.org/10.1007/s10706-004-5832-6.

[12] M. Heidemann, L. Bressani, J. Flores. Residual Shear Strength of a Residual Soil of Granulite. 2020. Soils and Rocks, São Paulo, 43(1): 31-41.

[13] K. Smith, R. Fanni, P. Chapman, D. Reid. Critical Stae Testeing of Tailings - Comparison between Various Tailings and Implications for Design. 2019. Proceeding of Tailings and Mine Waste 2019. November 17-20, Vancouver, Canada. 